\title{
Design and Analysis of Gearbox for SAE BAJA Competition
}

\author{
Anjali Mukeshkumar Sah ${ }^{1}$, Naved Anwar Husain Farooqui ${ }^{2}$. \\ ${ }^{1,2}$ Student, Department of Mechanical Engineering, \\ Rizvi College of Engineering, Mumbai, Maharashtra, India.
}

\begin{abstract}
This Design and analysis report of gearbox gives the theoretical and practical knowledge about the design, manufacturing and methodology of the gearbox for all terrain vehicles. This design of gearbox is as per the requirement of the BAJA SAE competition mentioned in the rule book of SAE BAJA INDIA 2020 [1]. Gearbox provides speed and torque conversions from the engine to the wheels. Gearbox is the main component in the transmission by which we can control the speed and provide the required amount of torque. This report gives an idea about how to set the perfect gear ratios as per the requirement of the BAJA SAE events.
\end{abstract}

Keywords - Transmission, ATV, SAE-BAJA, Gear box.

\section{INTRODUCTION}

The mechanism by which power is transmitted from an engine to the axle in a Vehicle is Transmission. Transmission is very important system to run vehicles. Transmission consists of Engine - CVT - Gearbox - axle Shaft - Wheels. CVT and Gearbox combinedly gives the power reduction ratios of engine to get the required amount of speed and torque. CVT means "Continuous Variable Transmission", it gives the variable amount of reduction ratio in between 0.4 to 3.1 which reduces the engine speed. [4]. CVT has fixed ratios as it can't be changed in standard CVT eg. CVTech [4]. Therefore, Gearbox plays an important role in the transmission. The main objective of this study is to design and analyse the gear box for all-terrain vehicles.

BAJA competition is majorly of three parts: Static, Dynamic and Endurance races [1]. Static events is the presentation event [1]. In Dynamic events the effective speed and torque have to be produced by the Gearbox to tackle all the obstacles [1]. Endurance race is the 4 hour continuous race in which we have to run the vehicles on the track with the maximum speed [1].

\section{METHODOLOGY}

Considering all the events of Baja competition, gearbox has been designed in such a way that weight of the gearbox should be reduced, gears tooth does not go under failure. And hence to get the accurate gear ratio, to fulfil all the requirements, the Reverse engineering method is adopted to design the 2-stage gearbox. This method is very effective as we already know our requirements. First we calculate maximum load for our design by which our design will not go under failure.
The approach is in the following ways:

Calculation of Gear Ratios $\rightarrow$ Design of Gears $\rightarrow$ Calculation of Loads acting on the gears $\rightarrow$ Gear Materials Selection $\rightarrow$ Analysis of gears $\rightarrow$ Calculation of factors depends upon the gears.

*Transmission Specifications:

i. Engine (as per the Rulebook of BAJA2020) [1]:

Engine: 19L232-0054-G1 (Briggs and Stratton).

Power: $10 \mathrm{HP}=7.46 \mathrm{~kW}$

Engine Torque $\left(\mathrm{T}_{\mathrm{e}}\right): 19.67 \mathrm{Nm}$.

Speed in rpm ( N ) : $3800 \mathrm{rpm}$.

ii. CVT: CVTech [4].

Ratios: 0.4 to 3.1 .

iii. Wheels Diameter : $0.584 \mathrm{~m} / 23$ inch.

iv. Weight of vehicles: $220 \mathrm{~kg}$.

v. Rolling Resistance $(\mu)$ : 0.08

Rolling Resistance is the force resisting the motion when a body rolls on a surface. It depends upon the types of road and design of wheels. 0.08 is the maximum condition for all types of road, below the concrete it`s 1 i.e. worst case scenario. vi. Efficiency of transmission ( E ) : $75 \%$ (Assumed by considering all the losses).

\section{CALCULATION OF GEAR RATIOS}

* Vehicles should not exceed the speed of $60 \mathrm{~km} / \mathrm{hr}$ as per the SAE BAJA2020 rules [1]. By considering all the requirements, maximum speed up to $60 \mathrm{~km} / \mathrm{hr}$ [1], acceleration and max. torque (considering $500 \mathrm{Nm}$ max torque), we conclude that the Gear Ratio of two stage gearbox should be $9.11: 1$ by the following calculations.

$$
\begin{aligned}
& \text { Max.Speed of Vehicles }=\frac{\mathrm{N} * \mathrm{C} * \mathrm{E} * 3.6}{\mathrm{C} . \mathrm{R} * \mathrm{G} . \mathrm{R} * 60} \\
& \qquad 60=\frac{3800 * 3.14 * 0.584 * 0.75 * 3.6}{0.6 * \mathrm{G} . \mathrm{R} * 60}
\end{aligned}
$$

Therefore, G.R = 8.72 ......(1)

Torque on Wheels $(\mathrm{T} . \mathrm{W})=\mathrm{T}_{\mathrm{e}} * \mathrm{C} . \mathrm{R} * \mathrm{G} . \mathrm{R} * \mathrm{E}$

$$
500=19.67 * 3.1 * \text { G.R } * 0.75
$$

Therefore, G.R = 10.933 .......(2)

For the high speed low gear ratio is required and for the high torque we need higher gear ratio. Since the speed of the vehicles should not exceed $60 \mathrm{~km} / \mathrm{hr}$ [1]. And to get the higher torque we concluded the gear ratio of 9.11:1 for the best performance.

Hence the first stage and second stages of gearbox should be 2.5 and 3.644 respectively. 
Gear type is helical gear, which is having an inclined pitch by which chances of the failure of the tooth will be minimum.

\begin{tabular}{|l|l|}
\hline Gearbox Type & 2 stage compound gearbox \\
\hline Gear Type & Helical Gear \\
\hline Gear Ratio & 9.11 \\
\hline $\begin{array}{l}\text { 1st stage Reduction } \\
\text { Ratio }\end{array}$ & 2.5 \\
\hline $\begin{array}{l}\text { 2nd stage Reduction } \\
\text { Ratio }\end{array}$ & 3.644 \\
\hline Pressure Angle $(\beta)$ & 20 degree \\
\hline Helix Angle $(\alpha)$ & 20 degree \\
\hline Module & 2.5 \\
\hline
\end{tabular}

\section{DESIGN OF GEARS}

For the selected gear ratio 9.11:1 the Pitch circle diameter (PCD) and No. of teeth $\left(\mathrm{T}_{\mathrm{n}}\right)$ is given by the following calculation.

Stage 1 gear ratio $=\underline{\text { No. of teeth of gear } 1}$

$$
=\frac{45}{18}=2.5
$$$$
\text { No. of teeth of pinion } 1
$$

PCD for Gear 1

$$
\mathrm{PCD}=\frac{\mathrm{T}_{\mathrm{n}}}{\operatorname{Cos} \alpha}=\frac{45 * 2.5}{\operatorname{Cos}(20)}=120.75 \mathrm{~mm}
$$

Same approach is done to get the rest values

\begin{tabular}{|c|l|l|l|l|}
\hline & \multicolumn{2}{|l|}{ Stage 1 } & \multicolumn{2}{l|}{ Stage 2 } \\
\hline & Pinion 1 & Gear 1 & Pinion 2 & Gear 2 \\
\hline No. of teeth & 18 & 45 & 17 & 62 \\
\hline Face Width & $16 \mathrm{~mm}$ & $16 \mathrm{~mm}$ & $16 \mathrm{~mm}$ & $16 \mathrm{~mm}$ \\
\hline PCD $(\mathrm{mm})$ & 48.88 & 120.72 & 46.23 & 162.95 \\
\hline
\end{tabular}

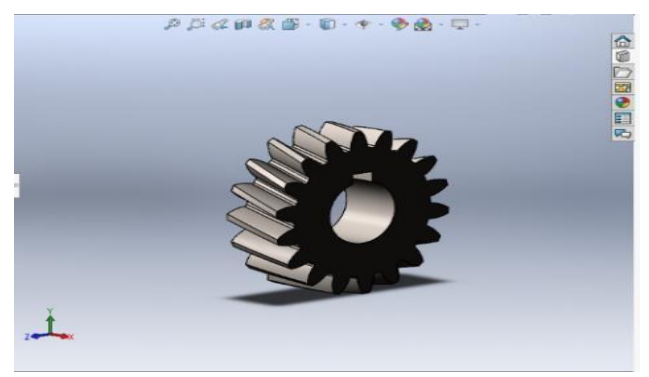

Stage-1 Pinion

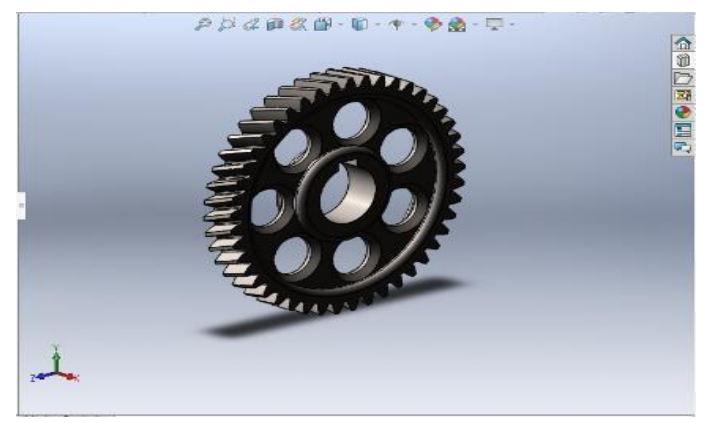

Stage -1 Gear

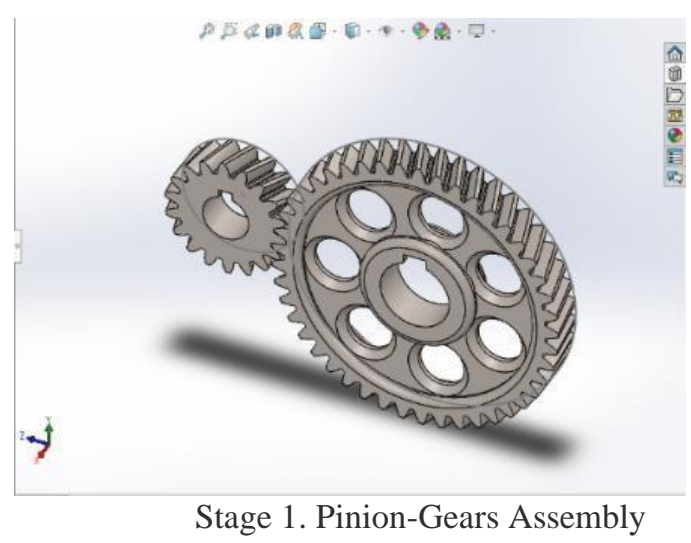

\section{CALCULATION OF LOADS ACTING ON THE GEARS}

For $1^{\text {st }}$ stage gears:

(1) Tangential Forces $(\mathrm{Ft})=\underline{2000 * \mathrm{~T}_{n}}$

$$
\begin{aligned}
& \text { P.C.D } \\
= & \frac{2000 * 45}{120.72} \\
= & 745.53 \mathrm{~N}
\end{aligned}
$$

(2) Axial forces $(\mathrm{Fx})=\mathrm{Ft} * \tan \beta$

$$
\begin{aligned}
& =745.53 * \tan (20) \\
& =274.63 \mathrm{~N}
\end{aligned}
$$

(3) Radial Forces ( Fr ) $=\mathrm{Ft} * \tan \alpha$

$$
\begin{aligned}
& =745.53 * \frac{\operatorname{Cos} \beta}{\frac{\tan (20)}{\cos (20)}} \\
& =288.77 \mathrm{~N}
\end{aligned}
$$

*Similar approach have to be done for the Second Stage Gears.

\section{GEAR MATERIALS SELECTIONS}

Gear materials selection is based on the amount of total load which acts on the gears or on gear tooth in the form of tensile strength or yield strength. The load which acts on the gears and gear tooth while dynamic and endurance races in the BAJA competition may cause the failure of the gears and breakage of gear tooth. The gear material should have sufficient strength to resist the failure due to breakage of the tooth.

Therefore this Materials has been selected:

\begin{tabular}{|l|c|c|}
\hline & Gear`s Materials & Gearbox Casing Materials \\
\hline Material & EN353 & Al6061 \\
\hline Tensile Strength & $680 \mathrm{MPa}$ & $310 \mathrm{MPa}$ \\
\hline $\begin{array}{l}\text { Yield } \\
\text { Strength }\end{array}$ & $440 \mathrm{MPa}$ & $276 \mathrm{MPa}$ \\
\hline Poisson's Ratio & 0.26 & 0.33 \\
\hline
\end{tabular}




\section{ANALYSIS OF GEARS}

Analysis has been done in ANSYS 16.0 on Workbench.

Stress Analysis of $1^{\text {st }}$ Stage Gears.
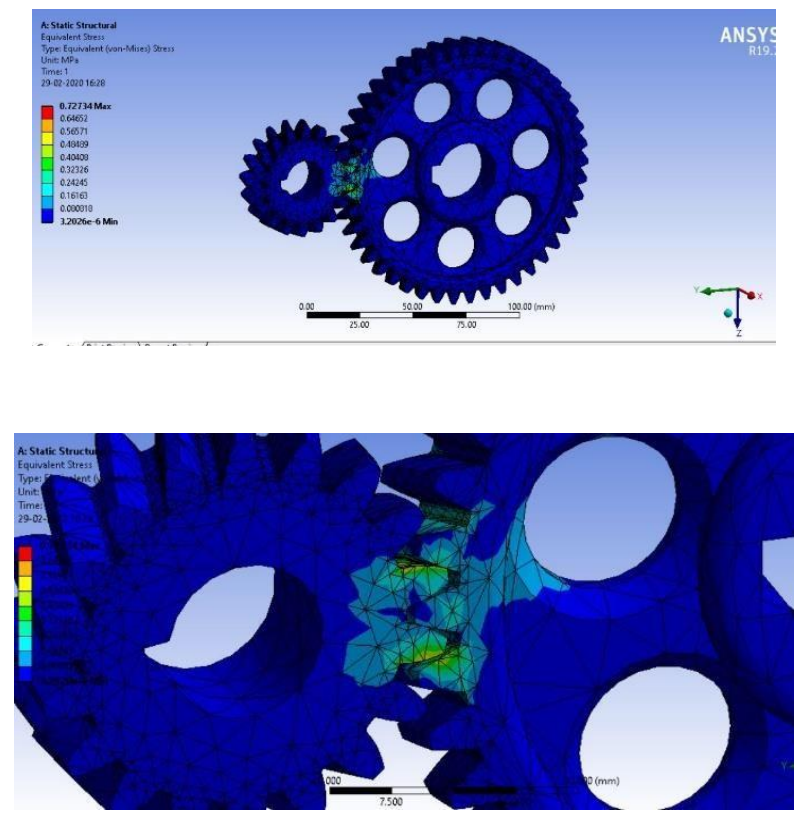

\section{CALCULATION OF FACTORS DEPANDS UPON THE GEARS}

1. Max.Speed of Vehicles $=\mathrm{N} * \mathrm{C} * \mathrm{E}^{*} 3.6$

$$
\begin{aligned}
& \text { C.R*G.R*60 } \\
& =\frac{3800 * 3.14 * 0.584 * 0.75 * 3.6}{0.6 * 9.11 * 60} \\
& =57.397 \mathrm{~km} / \mathrm{hr} .
\end{aligned}
$$

2. Acceleration:

> Tractive effort : It is the force act at the rims of the driving wheels of moving vehicles. It is required to accelerate the vehicle mass horizontally [7].

Tractive effort (T.E) $=\underline{T}_{e} *$ C.R $*$ G.R $* E$

$$
\begin{aligned}
& =\frac{19.67 * 3.1 * 9.11 * 0.75}{0.292} \\
& =1426.8 \mathrm{~N}
\end{aligned}
$$

$>$ Rolling Resistance : It the force resisting the motion when a body rolls on a surface.

Rolling Resistance (R.R) $=\mathrm{W} * \mu$

$$
\begin{aligned}
& =220 * 9.81 * 0.08 \\
& =172.656 \mathrm{~N}
\end{aligned}
$$

Total Resistance $(\mathrm{T} . \mathrm{R})=$ Air Resistance $($ A.R $)+$ Rolling Resistance ( R.R )

>Air resistance: A force acting opposite to the moving vehicle by the air.

* Since the speed of the vehicle should be less than and equal to $60 \mathrm{~km} / \mathrm{hr}$. The air resistance will be negligible.

T.R $=0+172.656=172.656 \mathrm{~N}$

Acceleration $=\underline{\text { T.E }- \text { T.R }}$

$$
\begin{aligned}
& =\frac{1426.8-172.656}{220} \\
& =5.7 \mathrm{~m} / \mathrm{s}^{2}
\end{aligned}
$$

$>$ Gradeability: The ability of the vehicles to climb the slope is gradeability.

$$
\begin{aligned}
\text { Gradeability } & =100 * \frac{\text { T.E }- \text { R.R })}{\mathrm{W}} \\
& =100 *\left(\frac{1426.8}{220 * 9.81}-0.08\right) \\
& =58.11 \%
\end{aligned}
$$

3. Torque on Wheels $(T . W)=T^{*}$ C.R*G.R* E

$$
\begin{aligned}
& =19.67 * 3.1 * 9.11 * 0.75 \\
& =416.625 \mathrm{Nm}
\end{aligned}
$$

Where, N: Speed of the engine (rpm)

$$
\mathrm{C} \text { : Circumference of Wheel (m) }
$$

E: Transmission Efficiency (\%)

C. R.: C.V.T Ratio

G.R.: Gear Ratio

$\mathrm{T}$ : Max engine Torque ( $\mathrm{Nm})$

$\mathrm{T}_{\mathrm{e}}$ : Engine Torque $(\mathrm{Nm})$

$\mathrm{R}$ : Radius of Wheel (m)

$\mathrm{W}$ : weight of Vehicles $(\mathrm{N})$

$\mathrm{m}$ : mass of the vehicles $(\mathrm{kg})$

$\beta$ : Pressure angle

$\alpha$ : Helix angle

$\mathrm{T}_{\mathrm{n}}$ : no. of Teeth

PCD : Pitch Circle Diameter (mm)

M: module of gears

\section{RESULT}

From all the Design, Analysis and calculation we concluded the following:

\begin{tabular}{|l|l|}
\hline Gear Material & EN353 \\
\hline Gear Casing Material & Al6061 \\
\hline Gearbox Type & $\begin{array}{l}\text { 2 Stage Compound Helical } \\
\text { Gearbox. }\end{array}$ \\
\hline Overall Gear Reduction Ratio & 9.11 \\
\hline 1st Stage Reduction Ratio & 2.5 \\
\hline 2nd Stage Reduction Ratio & 3.647 \\
\hline Module (For all 4 Gears) & 2.5 \\
\hline Pressure Angle & 20 Degree \\
\hline Helix Angle & 20 Degree \\
\hline $\begin{array}{l}\text { Face Width } \\
\text { For all 4 Gears ) }\end{array}$ & 16 \\
\hline $\begin{array}{l}\text { No. of teeth in 1st stage ( Gear, } \\
\text { Pinion ) }\end{array}$ & 45,18 \\
\hline $\begin{array}{l}\text { No. of teeth in 2st stage (Gear, } \\
\text { Pinion ) }\end{array}$ & 62,17 \\
\hline Max. Speed of Vehicles & $57.397 \mathrm{~km} / \mathrm{hr}$. \\
\hline Acceleration & $5.7 \mathrm{~m} / \mathrm{s}^{2}$ \\
\hline Gradeability & $58.11 \%$ \\
\hline Torque on Wheels & $416.625 \mathrm{Nm}$ \\
\hline
\end{tabular}

\section{CONCLUSION}

The main aim of this study was to design and analyse the transmission gearbox for the SAE BAJA competition by using reverse engineering method. The overall gear ratios have been determined to get the required speed and torque. 
Gear materials selection, number of teeth and gear type has been done to reduce the chances of failure. Analysis of the design has been done in the ANSYS 16.0 on workbench. And hence the gearbox is ready to transmit the required amount of speed and torque for the competition to tackle all the obstacles in the dynamic and endurance races in SAE BAJA competition.

\section{REFERENCES}

[1] Rule book of SAE BAJA INDIA 2020

[2] Gear Forces khkgears.net

[3] A textbook for Machine Design by R.S. /khurmi and J.K. Gupta.

[4] CVTech CVT catalog http://www.cvtechibc.com/en/client/pagesoussectiondf3b.html?cl ef $2=6$

[5] Boby George, Abin Jose, Adarsh John George, Ajay Augstine, Alvin Reji Thomas, "Innovative Design and Development of Transmission system of an off-road vehicle", International Journal of Scientific \& Engineering Research, Volume 7, Issue 3, March2016.

[6] Dr. V.K. Sunil, Sunil Kumar, Abhishek Singh, Abhishek Srivastava, Amit Sharma, Prashant Dobriyal, "Design And Development of a Transmission System for an all Terrain Vehicle "Volume:04, issue:05 May-2017.

[7] https://circuitglobe.com/tractive-effort.html 